\title{
Ten years of tiotropium: clinical impact and patient perspectives
}

This article was published in the following Dove Press journal:

International Journal of COPD

14 March 2013

Number of times this article has been viewed

\author{
Abebaw M Yohannes' \\ Martin J Connolly2 \\ Nicola A Hanania ${ }^{3}$ \\ 'Manchester Metropolitan University, \\ Department of Health Professions, \\ Manchester, UK; ${ }^{2}$ University \\ of Auckland, Freemasons' \\ Department of Geriatric Medicine, \\ Auckland, New Zealand; ${ }^{3}$ Pulmonary \\ and Critical Care Medicine, Baylor \\ College of Medicine, Houston, \\ TX, USA
}

\begin{abstract}
Tiotropium bromide is an anticholinergic agent that has gained worldwide acceptance as a first-line, once daily maintenance therapy for patients with moderate-to-severe chronic obstructive pulmonary disease. The purpose of this review is to synthesize the evidence base in the past 10 years on the development of tiotropium and its efficacy compared to other able interventions such as long-acting beta agonists (LABAs), as well as to assess its safety profile and its effects on health-related outcomes in patients with COPD. Treatment with tiotropium bromide has generally improved patients' health-related quality of life, reduced the number of patients suffering from acute exacerbations, decreased the number of hospitalizations, improved dyspnea, and reduced adverse events compared to placebo. In the past decade, several studies have examined the safety and efficacy of tiotropium in comparison to placebo and to LABAs (salmeterol, formoterol, and indacaterol) over periods ranging from 3 months to 48 months of follow-up. Head-to-head comparisons of tiotropium $18 \mu \mathrm{g}$ (once daily) with salmeterol $50 \mu \mathrm{g}$ (twice daily) in well-controlled trials demonstrated that tiotropium was superior in reducing acute exacerbation events and in improving quality of life. In a few short-term studies, indacaterol was comparable to tiotropium in its efficacy in improving health-related outcomes. Although the safety record of tiotropium has been exemplary in comparison to placebo, anticholinergic events such as dry mouth can be encountered in some patients. While the long-term safety of tiotropium when delivered in the HandiHaler ${ }^{\circledR}$ has been well documented, its delivery using the Respimat ${ }^{\circledR}$ Soft Mist Inhaler ${ }^{\mathrm{TM}}$ was associated with an elevated risk of cardiovascular complications, including increased mortality when compared to placebo. The exact mechanism for this is not known but is being investigated in a large multinational study that will evaluate the long-term safety of different doses of tiotropium delivered by the Respimat ${ }^{\circledR}$ soft mist inhaler versus the HandiHaler ${ }^{\circledR}$. Further studies are required to investigate the efficacy and safety of tiotropium in comparison with novel LABAs such as indacaterol and vilanterol, and with other emerging novel anticholinergic agents such as aclidinium bromide and NVA237 (glycopyrronium bromide).
\end{abstract}

Keywords: bronchodilator, tiotropium, salmeterol, indacaterol, LABA, chronic obstructive pulmonary disease

\section{Introduction}

Chronic obstructive pulmonary disease (COPD) is a major cause of morbidity and mortality throughout the world. Currently, the World Health Organization estimates that over 200 million people are living with COPD worldwide. ${ }^{1}$ COPD is projected to be the third leading cause of mortality and the seventh leading cause of burden of disability worldwide by $2030 .{ }^{1,2}$ In 2010 in the US alone, the cost of managing of COPD was approximately $\$ 49.9$ billion. $^{3}$ This included $\$ 29.5$ billion in direct health 
care expenditures (eg, hospitalizations and drug-related costs), $\$ 8$ billion in indirect morbidity costs (eg, absenteeism from work due to illness), and $\$ 12.4$ billion in indirect mortality costs.

COPD is a progressive disabling condition with irreversible airflow obstruction, which produces dyspnea. It is an inflammatory disease with systemic effects and is often associated with multiple comorbidities. Patients with inadequately treated moderate-to-severe COPD may experience two or more acute exacerbation events per annum. ${ }^{4}$ Frequent acute exacerbations are associated with a decline in lung function, increased dyspnea, reduced physical functioning, and impaired quality of life. ${ }^{1,2,4}$

Inhaled long-acting bronchodilators including anticholinergics and $\beta_{2}$-agonists constitute the cornerstone in the chronic management of COPD. Current long-acting bronchodilators include the long-acting inhaled anticholinergic drug, tiotropium, and the long-acting $\beta_{2}$-agonists (LABAs) formoterol, salmeterol, and indacaterol. Tiotropium and LABAs are recommended as the first-line of maintenance treatment for patients with moderate-to-severe COPD by the Global Initiative for Chronic Obstructive Lung Disease and the National Institute for Health and Clinical Excellence guidelines. ${ }^{4,5}$ The advancement of treatment from short-acting bronchodilators with multiple dosing per day to long-acting bronchodilators with once or twice daily dosing generally improved patients' management. Both tiotropium and LABAs are efficacious in improving lung function and quality of life, reducing the events of acute exacerbations and hospitalizations in patients with moderate-to-severe COPD. ${ }^{6-10}$ A single dosing per day of tiotropium bromide has therapeutic benefits including sustained bronchodilatation over 24 hours. It is convenient for the COPD patients' self-management and has a potential to improve patient adherence and compliance with treatment. ${ }^{11}$

Tiotropium bromide has been available since 2002, and is widely prescribed in over 110 countries worldwide with patient experience of over 25 million patient-years. ${ }^{12}$ It has improved patient-reported outcomes among patients with COPD, including improvements in airflow, hyperinflation, exercise tolerance, quality of life, and a reduction in acute exacerbation events and in mortality compared with placebo. $^{4,8}$

There are a number of excellent systematic reviews with meta-regression analysis pooled data, ${ }^{13-20}$ as well as recent Cochrane reviews, ${ }^{21,22}$ that examined the efficacy of tiotropium from well controlled, double-blind placebo-controlled clinical trials in patients with COPD. We decided not to perform another meta-regression analysis, as there are only one or two new papers that were not captured in previous reviews. However, the current review makes comments about these studies and refers to their relevant new findings. In this review, we focus on examining the evidence-base in the past 10 years following the development of tiotropium and its efficacy compared to other interventions such as LABAs. In addition we will examine the safety profile of tiotropium, as well as its effects on health-related outcomes in patients with COPD. We also explore the experiences of using tiotropium from the patients' perspectives.

\section{Pharmacology and mode of action}

Generally, the airflow limitation in COPD is the result of hyperplasia of mucosal glands and smooth muscle hypertrophy, which may lead to constriction of the bronchial smooth muscle in the small airways. ${ }^{23}$ Inflammatory changes in the airways of patients with COPD are associated with an increased cholinergic tone of the airway smooth muscles. ${ }^{23-25}$

Briefly, the acetylcholine discharged from parasympathetic system nerve endings activates the postsynaptic muscarinic M3 receptors present on airway smooth muscle and submucosal glands to induce bronchoconstriction and mucus secretion, accordingly. Inhaled anticholinergic drugs, including the short-acting muscarinic antagonists ipratropium bromide and oxitropium bromide (relievers), and long-acting tiotropium bromide (maintenance), play an important role by blocking the effects of vagally-derived acetylcholine on the airway smooth muscle contraction. ${ }^{23-27}$ The muscarinic receptors are involved in airway regulation as follows: the M1 receptors are located on the cholinergic ganglia, with the role of facilitating neural transmission; the $\mathrm{M} 2$ receptors are situated on the postganglion endings of the cholinergic fibers, with the role of limiting further acetylcholine release from postganglionic endings; and the M3 receptors are located on the smooth muscle cells, mucosal glands, and vascular endothelium in the airway wall, and induce bronchoconstriction, mucus hypersecretion, and airway wall edema. ${ }^{25,27}$ Tiotropium has a quaternary ammonium structure, which is derived from that of ipratropium. ${ }^{23}$ Tiotropium binds equally well to the M1 and M3 receptors; however, it dissociates very slowly from the M1 and M3 receptors compared with ipratropium, and more rapidly dissociates from the M2 receptors. ${ }^{24}$ Kinetics studies have demonstrated that tiotropium bromide dissociates 100 times more slowly than ipratropium bromide from M1 and M3. ${ }^{24}$

Thus, a single, once-daily dose of tiotropium has a long duration of action of over 24 hours. It also protects against 
the cholinergic effects of bronchoconstriction over a long period by increasing expiratory airflow, decreasing smooth muscle tone in the airways, and in turn reducing lung hyperinflation.

\section{Efficacy of tiotropium on mucus clearance}

The exact mechanism of tiotropium in mucus clearance is unclear; however, preliminary data indicate that tiotropium has a potential benefit to inhibit goblet cell metaplasia to reduce excess mucus production across in vivo and animal work. For example, Arai et $\mathrm{al}^{28}$ demonstrated that tiotropium was effective in mice by "inhibiting the neutrophil elastase induced goblet cell metaplasia in vivo and mucin production in vitro, probably mediated by suppression of inflammation and by a direct effect on epithelial cells." Thus, excess mucus production has a deleterious effect on the prognosis of COPD, and tiotropium may be useful in treating mucus overproduction in COPD. Further work is required on the efficacy and mechanisms of tiotropium in reducing mucus overproduction in patients with COPD.

The airways have normal defense mechanisms: (1) cilia's hair-like projections to trap and remove foreign agents; and (2) mucosal glands to produce normal mucus for hydration and to assist in the trapping and clearance of inhaled foreign particles. In COPD, the mucous glands during an exacerbation will produce copious amount of secretion (hypersecretion), which may contribute to airflow obstruction. This excess fluid, unless it is expectorated, will lead to troublesome coughs and increase the risk of developing chest infections. There is a great fear and concern among clinicians in the use of tiotropium during this situation, which might lead to "drying out of bronchial mucosa with increased viscosity, making it difficult for patients to clear secretions." 15 This is partly due to the effects of anticholinergics on the salivary glands, in which tiotropium is often implicated with elevated incidence of dry mouth in COPD patients.

However, there are no large studies that investigated the efficacy of tiotropium on mucus clearance and sputum properties in patients with COPD. In order to address these issues, two small-scale studies have examined the efficacy of tiotropium to enhance mucus clearance (sputum clearance ability) in patients with mild-to-moderate COPD. Hasani et $\mathrm{al}^{29}$ examined the efficacy of single $18 \mu \mathrm{g}$ oncedaily doses in comparison to placebo for lung mucociliary clearance in patients with COPD $(n=34)$ in a 3 -week randomized clinical study. Their findings indicated that there was no statistically significant difference in mucus clearance from the lungs between placebo and tiotropium. A recent study by Meyer et $\mathrm{al}^{30}$ assessed the efficacy of tiotropium $18 \mu \mathrm{g}$ once daily versus formoterol $12 \mu \mathrm{g}$ twice daily in the clearance of mucus secretion in mild-to-moderate COPD patients (20 males and four females) in a 2-week randomized study. They found that formoterol was superior in improving mucus clearance compared to tiotropium; these two studies' findings are inconclusive. ${ }^{29,30}$ Both studies have reported that aerosol deposition was significantly increased with tiotropium in that the transit pathway for mucus clearance was lengthened, and thus mucociliary clearance might increase slightly after tiotropium. Therefore, caution has to be exercised in the interpretation of these findings, as the subjects were predominately male and undergoing a short duration of treatment. Future studies are needed to examine the effects of these drugs (tiotropium versus formoterol) on mucus clearance in a larger sample with a longer term of treatment.

\section{Long-term safety of tiotropium bromide}

In 2006, Kesten et a $1^{14}$ examined the safety and adverse events of tiotropium $(n=4435)$ versus placebo $(n=3384)$ in a pooled data analysis of 19 randomized, double-blind, placebo-controlled clinical trials lasting up to 12 months. Their findings indicated that tiotropium was superior to placebo, with a $36 \%$ reduction in dyspnea symptoms, a $28 \%$ reduction in COPD exacerbations, a $24 \%$ reduction in all causes of mortality, and a $43 \%$ reduction in cardiovascular mortality.

In 2008 , Singh et $\mathrm{al}^{15}$ explored the efficacy of tiotropium and its adverse events in 17 trials that recruited 13,645 patients with a follow-up duration of 6 weeks to 5 years. Of these, 6984 participants were in the tiotropium group and 6661 were in the placebo or comparator (such as salmeterol, ipratropium, or salbutamol) group. They found that tiotropium was associated with an elevated risk of myocardial infarction with a relative risk $(\mathrm{RR})$ of $1.52(95 \%$ confidence interval (CI) 1.04-2.22), stroke (RR 1.46, 95\% CI 0.81-2.62), cardiovascular death (RR 1.92, 95\% CI 1.23-3.00), and all causes of mortality (RR $1.29,95 \%$ CI 1.00-1.65) compared to the placebo or comparator group. These findings have been a source of concern for physicians and patients, but have been widely debated in academic communities.

To address these issues in 2010 , Celli et al ${ }^{16}$ conducted a metaregression analysis of 30 double-blind, randomized controlled trials comprised of 10,846 (tiotropium) and 8699 (placebo) patients, with 4 weeks to 4 years of follow-up. 
They found that the incidence rate (IR) for all causes of mortality was 3.44 (tiotropium) and 4.10 (placebo) per 100 patient-years, and the IR for cardiovascular mortality was 2.15 (tiotropium) and 2.67 (placebo) per 100 patient-years. These findings are equivalent to a $12 \%$ reduction in all causes of mortality and a $23 \%$ reduction in cardiovascular mortality, which are in favor of tiotropium compared with placebo. In addition, tiotropium was superior in reducing myocardial infarction, cardiac failure, and stroke events $(22 \%, 18 \%$, and $3 \%$, respectively) compared with placebo. These findings indicate that tiotropium has a better safety profile in reducing all causes of mortality and cardiovascular events compared with placebo. One of the main strengths of this analysis was the inclusion of a study with the largest and longest duration of follow-up, the Understanding Potential Long-term Impacts on Function with Tiotropium (UPLIFT) study. ${ }^{8}$ This latter trial was a 4-year randomized placebo-controlled trial of tiotropium $(n=2987)$ versus placebo $(n=3006)$. The findings showed that tiotropium was superior in reducing exacerbation events by $14 \%$ and in reducing all causes of mortality by $11 \%$ compared with placebo. Tiotropium was associated with a delay in the time to the first exacerbation, with a median of 16 months compared with 12.5 months in the placebo group. There were significant differences in the changes from mean observed in the St George's Respiratory Questionnaire (SGRQ) scores ranging from 2.3 to 3.3 $(P<0.001)$ in favor of tiotropium during the study period. In addition, a significant proportion of COPD patients in the tiotropium group had an improvement of over four points in the SGRQ score (clinically significant) compared to placebo. This study and others provide credible evidence for the superiority of tiotropium over placebo in improving health-related outcomes. ${ }^{8,17,18}$

\section{Tiotropium bromide in comparison with LABAs}

Tiotropium and LABAs are currently prescribed as maintenance bronchodilator therapy for patients with moderate-tosevere COPD., ${ }^{4,32}$ Studies comparing the efficacy of the three available LABAs and tiotropium include: tiotropium versus salmeterol (three studies); $6,31,33$ tiotropium versus formoterol (two studies) $;^{34,35}$ and tiotropium versus indacaterol (two studies). ${ }^{35,36}$

In 2003, Brusasco et $\mathrm{al}^{31}$ examined the efficacy of tiotropium bromide $18 \mu \mathrm{g}$ versus salmeterol $50 \mu \mathrm{g}(\mathrm{n}=1207)$ and placebo with 6 months' duration in a double-blind, double-dummy, parallel group trial. Their findings indicated that tiotropium was superior in improving quality of life as measured by the SGRQ with a mean 4.2 (clinically significant) difference in SGRQ scores compared to salmeterol (difference of 2.8) and placebo (difference of 1.5). In addition, fewer exacerbation events occurred in the tiotropium group in comparison to both the salmeterol and placebo groups. Both salmeterol and tiotropium groups showed an improved dyspnea score. A potential drawback of this study includes the fact that over three-quarters of the subjects were male.

Briggs et al $^{33}$ investigated $(n=653)$ the impact of tiotropium bromide $(n=328)$ versus salmeterol $(n=325)$ in changes across lung function and in the occurrence of acute exacerbations in a 3-month follow-up study. Tiotropium statistically and significantly improved forced expiratory volume in one second $\left(\mathrm{FEV}_{1}\right)$ compared with salmeterol from baseline (167 mL versus $130 \mathrm{~mL}, P<0.01)$. However, both drugs produced clinically significant improvements in lung function beyond the minimal clinically important difference, which is $100 \mathrm{~mL}$. There was no difference in the incidence of COPD exacerbations or in adverse events between the two groups. There was, however, less rescue medication use in the tiotropium group. It is not clear from the study whether the difference obtained in $\mathrm{FEV}_{1}$ had beneficial effects in reducing dyspnea or improving quality of life, as these parameters were not examined.

Vogelmeier et $\mathrm{al}^{6}$ conducted the largest study $(\mathrm{n}=7376)$ to examine the long-term benefits of tiotropium $18 \mu \mathrm{g}$ once daily, $(n=3707)$ versus salmeterol $50 \mu \mathrm{g}$ twice daily $(n=3669)$ in a 1-year study. The primary objective of the study was to examine the impact of these drugs in preventing acute exacerbations in patients with COPD. They found that tiotropium (compared with salmeterol) was associated with greater time to the first exacerbation (187 days versus 145 days), with a $17 \%$ reduction in risk (hazard ratio (HR), 0.83 ; 95\% CI $0.77-0.90, P<0.001$ ), and increased time to the first severe exacerbation with a $28 \%$ reduction in risk (HR 0.72; 95\% CI 0.61-0.85, $P<0.001$ ). In addition, tiotropium also reduced the annual number of severe exacerbations with a $27 \%$ reduction in these events (HR 0.73 ; 95\% CI $0.66-0.82, P<0.001)$. However, there were no significant differences between the two groups in patients' experiences of the number of adverse events, discontinuation of treatment, the number of patients who required hospitalization, or mortality.

In a relatively small study $(\mathrm{n}=71)$ van Noord et $\mathrm{al}^{34}$ examined the efficacy of tiotropium $18 \mu \mathrm{g}$ in comparison to formoterol $12 \mu \mathrm{g}$ twice daily, as well as when both drugs were combined (tiotropium plus formoterol), in a 6-week 
study. The study design was a double-blind, three-way, crossover study. The primary end-point was improvement in $\mathrm{FEV}_{1}$. Their findings indicate that tiotropium significantly improved $\mathrm{FEV}_{1}$ during the daytime compared to formoterol. The combination of tiotropium plus formoterol was much superior in improving $\mathrm{FEV}_{1}$ compared to each single drug. Furthermore, Hanania et al, ${ }^{35}$ in a larger study $(n=155)$ of a similar design conducted over the course of 6 weeks, produced similar findings. There were no statistically significant differences in terms of adverse events; however, these studies are relatively small and of very short duration.

In 2010, Donohue et $\mathrm{al}^{36}$ compared the efficacy of tiotropium bromide $18 \mu \mathrm{g}$ once daily $(\mathrm{n}=420)$ versus indacaterol $150 \mu \mathrm{g}$ twice daily $(\mathrm{n}=420)$, versus indacaterol $300 \mu \mathrm{g}$ twice daily $(n=418)$, and versus placebo $(n=435)$ in a 26-week, randomized, placebo-controlled, parallel group trial. The findings showed that indacaterol in both doses, as well as tiotropium, significantly increased $\mathrm{FEV}_{1}$ values by $180 \mathrm{~mL}$ and $140 \mathrm{~mL}$, respectively. There was a statistically significant difference at 26 weeks in the total SGRQ score and Transition Dyspnea Index (TDI) score (an increase in more than one point in the total score) in both indacaterol groups. Tiotropium showed statistically significant difference in the TDI score, not in the total SGRQ score. However, there were no statistically significant differences in the incidence of adverse events between the indacaterol and tiotropium groups. Further studies are required to determine the efficacy of indacaterol in comparison with tiotropium in patient health-related outcomes with 1-year or greater longterm follow-up.

Buhl et $\mathrm{al}^{37}$ compared the efficacy of tiotropium $18 \mu \mathrm{g}$ once daily $(\mathrm{n}=801)$ versus indacaterol $150 \mu \mathrm{g}$ once daily $(n=797)$ in terms of efficacy, safety, and tolerability in 12-week interventions. They found that indacaterol was superior in improving quality of life (SGRQ total score) compared with tiotropium, with the mean change from baseline of -5.1 and -3.0 , respectively $(P<0.001)$. In addition, indacaterol was significantly more likely (odds ratio $(\mathrm{OR})$ $1.49, P<0.001)$ to achieve a clinically relevant improvement in dyspnea compared to tiotropium. The two treatment arms were well tolerated, and adverse event profiles were similar in both groups. Again, such a short-term intervention does not provide us with information on the efficacy of indacaterol in reducing acute exacerbations or mortality.

Kerwin et $\mathrm{al}^{38}$ examined the efficacy and safety of $50 \mu \mathrm{g}$ once daily NVA237 (glycopyrronium bromide) in comparison to tiotropium $18 \mu \mathrm{g}$ once daily and placebo in a 52-week treatment follow-up. They found that NVA237 was comparable to tiotropium and superior to placebo in improving lung function, dyspnea, and health status, and in reducing exacerbation events and the use of rescue medication in moderate-to-severe COPD patients. The proportion of patients that achieved the minimally important difference in the total SGRQ score ( $\geq 4$ point reduction) was similar in the NVA237 (54.3\%) and tiotropium (59.4\%) groups versus placebo $(50.8 \%)$. The antimuscarinic side-effects, such as dry mouth and urinary tract infection, are similar and relatively small in the three groups in this study. Four patients reported atrial fibrillation in the NVA237 group compared to none in the placebo or tiotropium groups. The NVA237 has the potential to be an alternative to tiotropium in the treatment of moderate-to-severe COPD patients; however, further studies are required to determine the efficacy and safety of NVA237 over a 1-year treatment follow-up in a larger sample size when compared to tiotropium.

\section{Safety and tolerability}

The most commonly reported adverse event was dry mouth, with a total of ten studies reporting incidence. ${ }^{21,22}$ The cumulative incidence was $7.4 \%$ in tiotropium patients, $3.9 \%$ in ipratropium patients, $1.6 \%$ in salmeterol patients, and $2.0 \%$ in placebo patients. The incidence of dry mouth was significantly increased in eight studies $(\mathrm{n}=4998)$, which compared tiotropium with placebo $(\mathrm{OR}=3.19 ; 95 \% \mathrm{CI}$ : 1.79-5.70; $P<0.001)$

Studies have consistently reported that tiotropium is safe and well tolerated in clinical trials that ranged from 3 months to 48 months. ${ }^{21}$ In most studies, the completion rate was slightly higher in the tiotropium group (77\%-98\%) compared with placebo $(71 \%-92 \%)$. However, in the UPLIFT 4-year follow-up study, ${ }^{8}$ the completion rate was relatively low for both the tiotropium and placebo groups (63\% versus 55\%, $P<0.0001$, respectively); this might be related to the long duration of follow-up. The most commonly reported reasons for withdrawal from the studies were worsening symptoms and adverse events. Dry mouth was consistently reported in most studies, with a high prevalence in the tiotropium group compared with placebo. ${ }^{21,22}$ Other adverse events associated with tiotropium include constipation, tachycardia, blurred vision, urinary retention, raised intraocular pressure, and angina pectoris.

A recent study investigated the medical records database of general practitioners in the UK in terms of new users of long-acting anticholinergic therapy (tiotropium HandiHaler ${ }^{\circledR}$, Boehringer Ingelheim Pharmaceuticals, Inc, Ridgefield, CT, USA) $(n=4767)$ in comparison with new users of LABA 
monotherapy $(\mathrm{n}=6073) .{ }^{39}$ They found that more cardiovascular events occurred when using tiotropium compared with LABA for stroke (HR, 1.49; 95\% CI 0.91-2.15), myocardial infarction (HR, 1.38, 95\% CI 0.88-2.15), and angina (HR 1.26; 95\% CI 0.72-2.21) compared with LABA. In contrast, tiotropium treatment was associated with a lower risk of total mortality (HR 0.70, 95\% CI 0.56-0.89) and of asthma exacerbations (HR 0.46, 95\% CI 0.36-0.57). These data provide us with inconclusive evidence. There are issues in the databases that potentially affect the data analysis of the study. These include incomplete responses, the absence of lung function measures, and a lack of information on the cause(s) of death. The main messages that clinicians should consider when prescribing these drugs are to focus on appropriate assessments, regularly monitor patients, and practice vigilance for potential adverse events.

\section{Delivery devices}

Tiotropium may be delivered via one of two inhaler devices - the HandiHaler ${ }^{\circledR}$ Dry Powder Inhaler $(18 \mu \mathrm{g}$ once daily; Boehringer Ingelheim Pharmaceuticals, Inc), and the Respimat ${ }^{\circledR}$ Soft Mist ${ }^{\mathrm{TM}}$ Inhaler (5 $\mu \mathrm{g}$ once daily or $10 \mu \mathrm{g}$ once daily; Boehringer Ingelheim Pharma $\mathrm{GmbH}$ and $\mathrm{Co}, \mathrm{KG}$, Ingelheim, Germany). There is some controversy surrounding the long-term safety of tiotropium delivered using the Respimat ${ }^{\circledR}$ device. A recent systematic review investigated the safety profile of five randomized controlled trials $(n=6522)$ examining tiotropium delivered using the Respimat $^{\circledR}$ inhaler in comparison with placebo. ${ }^{19}$ They found that using the tiotropium Respimat ${ }^{\circledR}$ inhaler was associated with a significantly increased risk of mortality (90/3686 versus 47/2836; RR 1.52, 95\% CI, 1.06-2.16; $P=0.02$ ). In addition, Dog and co-workers ${ }^{20}$ investigated the efficacy of RCTs that employed Soft Mist Inhaler, tiotropium HandHaler, LABAs, and inhaled corticosteroids (ICS) and LABA-ICS combination with at least 6-month duration of patients with COPD. This meta-analysis was conducted to determine the pooled estimate odd ratios (OR) of deaths for each comparison, which included 42 trials with 52,516 COPD patients. They showed that Soft Mist Inhaler was associated with increased risk of overall death compared with placebo (OR 1.51; 95\% CI 1.06 to 2.19), tiotropium Handihaler (OR 1.65; 95\% CI 1.13 to 2.43 ), LABA (OR 1.63 ; 95\% CI 1.10 to 2.44 ), and LABA-ICS (OR 1.90; 95\% CI 1.28 to 2.86). The elevated risk of cardiovascular death was related to patients with severe COPD and at a higher daily dose. The exact mechanisms behind this finding are not entirely clear. One potential explanation might be that the improved delivery afforded by the mist inhaler could possibly increase plasma concentrations of tiotropium and therefore increase risks. The Medicines and Healthcare Products Regulatory Agency currently advises a cautious approach when using the Respimat ${ }^{\circledR}$ inhaler $5 \mu \mathrm{g}$ in patients with arrhythmias. ${ }^{40} \mathrm{~A}$ study is underway to explore a "head-to-head" comparison of the tiotropium Respimat ${ }^{\circledR}$ mist inhaler with the tiotropium HandiHaler ${ }^{\circledR}$.

\section{Discontinuation of therapy}

Early discontinuation of therapy in clinical studies is often accompanied by a host of difficulties in dealing with the statistical analysis of the data associated with type 2 errors. Early discontinuation especially poses challenges in interventional studies that focus on disease progression with long-term follow-up. A recent clinical guideline using a systematic review for the management of COPD reported that the prevalence rate of early discontinuation ranges from $27 \%$ to $53 \%$ in the long-term studies. ${ }^{41}$ Premature withdrawals from these studies often follow similar patterns and trends. For example, studies have consistently reported that an elevated percentage of COPD patients in the placebo groups discontinue treatment compared to those in the active treatment groups, both at baseline and during the study. ${ }^{42,43}$ It may be that being in a placebo group (even when blinded) may have unwanted psychological demoralizing effects in terms of a lack of treatment efficacy.

In this context, Decramer et $\mathrm{al}^{43}$ examined factors that contribute to the premature discontinuation of therapy, including the characteristics of patients among the placebo and tiotropium groups from the UPLIFT study. Their findings indicate that a higher percentage of patients withdrew from the placebo group when compared with the tiotropium group (45\% versus $37 \%, P<0.001)$. In addition, early withdrawal from the study was associated with older age, female gender, current smoking status, number of pack years smoked, worse SGRQ scores, and "assignment" to the placebo group. Knowing these factors early in the design stage of a study may be helpful to provide appropriate support for the patients during the study.

\section{Adherence to tiotropium therapy}

Very few studies have investigated patient adherence to inhaled medications including tiotropium. ${ }^{42}$ Two large prescription claim database studies from The Netherlands and Canada have reported that patients' adherence (persistence) to tiotropium was far higher than that of other comparators (eg, LABAs). ${ }^{44,45}$ For example, in The Netherlands, ${ }^{44}$ almost $37 \%$ of the new users of tiotropium continued treatment for 12 months, compared with 14\% for ipratropium, 13\% for 
LABA, and $17 \%$ for LABAs plus inhaled corticosteroids (ICSs). In this study, there were significant differences in the baseline characteristics (eg, a higher percentage of male COPD patients and a higher number of comorbid chronic diseases) in the tiotropium group compared to the other groups. Similar trends were also observed in Canada in a 1-year follow-up study, with 53\% adherence for tiotropium compared with other therapies (7\% to $30 \%$; all $P<0.001$ ), including ipratropium, ipratropium plus salbutamol, formoterol, formoterol plus budesonide, salmeterol, and salmeterol plus fluticasone. ${ }^{45}$ Thus, it is important that COPD patients should receive appropriate education at the time of prescription, and that they are regularly monitored for their use by health care professionals.

\section{Effects of tiotropium on patient- reported outcomes Health-related quality of life}

In 2011, Yohannes et $\mathrm{al}^{18}$ examined quality of life in metaregression analysis of 20 studies $(n=22,468$ COPD patients) comparing tiotropium with placebo. They found that the proportion of COPD patients who obtained a clinically significant change (a four-unit change) in the SGRQ score was significantly higher in the tiotropium group compared with the placebo group. The proportion of patients who achieved a statistically significant improvement in the SGRQ was greater with tiotropium compared with placebo. In addition, a recent Cochrane 28 meta-regression analysis conducted in 2012 ( $n=22$ studies) reported that tiotropium was effective, with the mean quality of life (SGRQ) score demonstrating a statistically significant difference over placebo (OR $-2.89 ; 95 \% \mathrm{CI}-3.35$ to $-2.44 ; P<0.001) .{ }^{21}$

\section{Dyspnea}

Two studies from those mentioned above $(n=1489)$ examined the proportion of COPD patients who obtained a clinically significant change (a one-unit change) in the TDI for tiotropium compared with placebo. ${ }^{31,32}$ This was further confirmed with a meta-regression analysis from our department, ${ }^{17}$ which showed a statistically significant improvement in the dyspnea score in favor of tiotropium compared with placebo (OR 1.96; 95\% CI 1.58-2.44; $P<0.001$ ). These improvements have not reached clinically relevant thresholds for the SGRQ scores.

\section{COPD exacerbations}

A recent Cochrane review examined the efficacy of tiotropium in comparison to placebo $(n=22$ studies $)$ in preventing acute exacerbations and COPD-related hospitalizations in patients with COPD. ${ }^{21}$ Tiotropium treatment significantly reduced the number of patients suffering from acute exacerbations (OR 0.78; 95\% CI 0.70-0.87). This translates into a need to treat 16 patients (95\% CI 10-36) with tiotropium for a year in order to avoid one additional patient suffering from an exacerbation. In addition, tiotropium treatment led to fewer hospitalizations due to exacerbations compared to placebo, but there was no statistically significant difference in all causes of hospitalizations.

Short et $a 1,{ }^{46}$ in a retrospective study using the National Health Service database (mean follow-up was 4.65 years), ${ }^{46}$ examined the potential benefits of tiotropium in conjunction with ICSs and LABA ( $\mathrm{n}=1875$ COPD patients) versus ICSs plus LABA ( $\mathrm{n}=996$ COPD patients). Their findings showed that triple therapy (tiotropium, ICSs, and LABA) was superior to double therapy (ICS and LABA). A combination of triple treatment approach demonstrated $35 \%$ reduction in all causes of mortality $(95 \% \mathrm{CI}, 0.57-0.75$; $\mathrm{P}=0.001), 15 \%$ reduction in hospital admission $(95 \% \mathrm{CI}$, $0.73-0.99 ; \mathrm{P}=0.04)$ and $29 \%$ reduction in the use of oral corticosteroid bursts $(0.71$ (95\% CI, 0.63-0.80; $P<0.001)$, compared with double therapy, respectively. Thus, the findings give some credence for the evidence surrounding the use of triple therapy in the management of moderate-to-severe COPD patients. Further studies are required in a prospective study with longer treatment follow-ups to show the efficacy of triple therapy versus double therapy using randomized controlled trials.

\section{Where do we go from here?}

The majority of key randomized controlled trials have reported that tiotropium is superior in reducing cardiovascular events and all causes of mortality compared to placebo; ${ }^{21}$ in contrast, one systematic review reported the opposite. ${ }^{15}$ It is important to note that COPD itself is associated with an elevated risk for cardiovascular events and mortality. Future studies are required to clarify these controversial issues.

While the long-term safety of tiotropium when delivered in the HandiHaler ${ }^{\circledR}$ has been well documented, its delivery using the Respimat ${ }^{\circledR}$ Soft Mist ${ }^{\mathrm{TM}}$ Inhaler was associated with an elevated risk of cardiovascular complications (including mortality) when compared to placebo. The exact mechanism for this is not known but is being investigated in a large multinational study that will evaluate the long-term safety profile of different doses of tiotropium delivered by the Respimat ${ }^{\circledR}$ Soft Mist ${ }^{\mathrm{TM}}$ Inhaler versus the HandiHaler ${ }^{\circledR}$. 
Potential areas for future research in order to investigate the efficacy of tiotropium may include to:

- explore the long-term cardiovascular safety of tiotropium delivered in Respimat ${ }^{\circledR}$ in patients with COPD;

- investigate the role of tiotropium when added to a LABA (olodaterol) in one delivery system;

- examine any differences in efficacy and safety between tiotropium and new LABAs in development;

- determine the utility of tiotropium when used in patients with mild COPD.

\section{Conclusion}

The available literature on the majority of the randomized controlled trials report that tiotropium is clinically effective in improving lung function and quality of life, and in reducing dyspnea in patients with moderate to severe COPD. Although the safety record of tiotropium has been exemplary in comparison to placebo, anticholinergic events such as dry mouth can be encountered in some patients.

Further studies are required to investigate the efficacy and safety of tiotropium in comparison with novel LABAs such as indacaterol and vilanterol, and with other emerging novel anticholinergic agents such as aclidinium bromide and NVA237 (glycopyrronium).

\section{Disclosure}

The authors report no conflicts of interest in this work.

\section{References}

1. World Health Organization. COPD predicted to be third leading cause of death in 2030 [webpage on the Internet]. Geneva: World Health Organization; 2008. Available from: http://www.who.int/respiratory/copd/World_Health_Statistics_2008/en/index.html. Accessed February 12, 2013.

2. Mathers CD, Loncar D. Projections of global mortality and burden of disease from 2002 to 2030. PLoS Med. 2007;3(11):e442.

3. US Department of Health and Human Services. National Institutes of Health. National Heart Lung and Blood Institute. Morbidity and Mortality: 2009 Chart book on Cardiovascular, Lung and Blood Diseases. [webpage on the Internet]. Available from: http://www.nhlbi.nih.gov/ about/factbook-09/chapter4.htm. Accessed February 12, 2013.

4. Global Initiative for Chronic Obstructive Lung Disease (GOLD). Global strategy for the diagnosis, management, and prevention of COPD [webpage on the Internet]. Vancouver, WA: Global Initiative for Chronic Obstructive Lung Disease; 2011 [updated Dec 2011]. Available from: http://www.goldcopd.org/uploads/users/files/GOLD_Report_2013.pdf. Accessed February 12, 2013.

5. National Institute for Health and Clinical Excellence. Chronic Obstructive Pulmonary Disease: Management of Chronic Obstructive Pulmonary Disease in Adults in Primary and Secondary Care. London: National Clinical Guideline Centre; 2010. Available from: http://guidance.nice. org.uk/CG101/Guidance/pdf/English. Accessed February 12, 2013.

6. Vogelmeier C, Hederer B, Glaab T, et al; for POET-COPD Investigators. Tiotropium versus salmeterol for the prevention of exacerbations of COPD. N Engl J Med. 2011;364(12):1093-1103.
7. Calverley PM, Anderson JA, Celli B, et al; for TORCH investigators. Salmeterol and flucticasone propionate and survival in chronic obstructive pulmonary disease. $N$ Engl J Med. 2007;356(8): 775-789.

8. Tashkin DP, Celli B, Senn S, et al; for UPLIFT Study Investigators. A 4-year trial of tiotropium in chronic obstructive pulmonary disease. N Engl J Med. 2008;359(15):1543-1554.

9. Wedzicha JA, Calverley PM, Seemungal TA, Hagan G, Ansari Z, Stockley RA; for INSPIRE Investigators. The prevention of chronic obstructive pulmonary disease exacerbations by salmeterol/fluticasone propionate or tiotropium bromide. Am J Respir Crit Care Med. 2008;177(1):19-26.

10. Aaron SD, Vandehmheen KL, Fergusson D, et al; for Canadian Thoracic Society/Canadian Respiratory Clinical Research Consortium. Tiotropium in combination with placebo, salmeterol, or fluticasonesalmeterol for treatment of chronic obstructive pulmonary disease: a randomized trial. Ann Intern Med. 2007;146(8):545-555.

11. Bourbeau J, Bartlett SJ. Patient adherence in COPD. Thorax. 2008; 63(9):831-838.

12. Boehringer Ingelheim GmbH. Annual Report 2011. Ingelheim: Boehringer Ingelheim $\mathrm{GmbH}$; 2011. Available from: http://www. boehringer-ingelheim.com/content/dam/internet/opu/com_EN/ document/01_news/08_APC/APC_2012/BoehringerIngelheim_ Annual_Report_2011_complete.pdf. Accessed November 8, 2012.

13. Barr RG, Bourbeau J, Camargo CA, Ram FS. Tiotropium for stable chronic obstructive pulmonary disease: a meta-analysis. Thorax. 2006; 61(10):854-862.

14. Kesten S, Jara M, Wentworth C, Lanes S. Pooled clinical trials analysis of tiotropium safety. Chest. 2006;130(6):1695-1703.

15. Singh S, Loke YK, Furberg CD. Inhaled anticholinergics and risk of major adverse cardiovascular events in patients with chronic obstructive pulmonary disease: a systematic review and meta-analysis. JAMA. 2008;300(12):1439-1450.

16. Celli B, Decramer M, Leimer I, Vogel U, Kesten S, Tashkin DP. Cardiovascular safety of tiotropium in patients with COPD. Chest. 2010; 137(1):20-30

17. Halpin D, Menjoge S, Viel K. Patient-level pooled analysis of the effect of tiotropium on COPD exacerbations and related hospitalisations. Prim Care Respir J. 2009;18(2):106-113.

18. Yohannes AM, Willgoss TG, Vestbo J. Tiotropium for treatment of stable COPD: a meta-analysis of clinically relevant outcomes. Respir Care. 2011;56(4):477-487.

19. Singh S, Loke YK, Enright PL, Furberg CD. Mortality associated with tiotropium mist inhaler in patients with chronic obstructive pulmonary disease: systematic review and meta-analysis of randomised controlled trials. BMJ. 2011;342:d3215.

20. Dong YH, Lin HH, Shau WY, Wu YC, Chang CH, Lai MS. Comparative safety of inhaled medications in patients with chronic obstructive pulmonary disease: systematic review and mixed treatment comparison meta-analysis of randomised controlled trials. Thorax. 2013;68(1):48-56.

21. Karner C, Chong J, Poole P. Tiotropium versus placebo for chronic obstructive pulmonary disease. Cochrane Database Syst Rev. 2012; 7:CD009285.

22. Chong J, Karner C, Poole P. Tiotropium versus long-acting beta-agonists for stable chronic obstructive pulmonary disease. Cochrane Database Syst Rev. 2012;9:CD009157.

23. Barnes PJ. The role of anticholinergics in chronic obstructive pulmonary disease. Am J Med. 2004;117 Suppl 12A:24S-32S.

24. Baterman ED, Rennard S, Barnes PJ, et al. Alternative mechanisms for tiotropium. Pulm Pharmacol Ther. 2009;22(6):533-542.

25. Novelli F, Malagrinò L, Dente FL, Paggiaro P. Efficacy of anticholinergic drugs in asthma. Expert Rev Respir Med. 2012;6(3): 309-319.

26. Belmonte KE. Cholinergic pathways in the lungs and anticholinergic therapy for chronic obstructive pulmonary disease. Proc Am Thorac Soc. 2005;2(4):297-304. 
27. Gosens R, Zaggsma J, Meurs H, Halayko J. Muscarine receptor signaling in the pathophysiology of asthma and COPD. Respir Res. 2006;7:73.

28. Arai N, Kondo M, Izumo T, Tamaoki J, Nagai A. Inhibition of neutrophil elastase-induced goblet cell metaplasia by tiotropium in mice. Eur Respir J. 2010;35(5):1164-1171.

29. Hasani A, Toms N, Agnew JE, Sarno M, Harrison AJ, Dilworth P. The effect of inhaled tiotropium bromide on lung mucociliary clearance in patients with COPD. Chest. 2004;125(5):1726-1734.

30. Meyer T, Reitmeir P, Brand P, et al. Effects of formoterol and tiotropium bromide on mucus clearance in patients with COPD. Respir Med. 2011;105(6):900-906.

31. Brusasco V, Hodder R, Miravitlles M, Korducki L, Towse L, Kesten S. Health outcomes following treatment for six months with once daily tiotropium compared with twice daily salmeterol in patients with COPD. Thorax. 2003;58(5):399-404.

32. Casaburi R, Mahler DA, Jones PW, et al. A long-term evaluation of once-daily inhaled tiotropium in chronic obstructive pulmonary disease. Eur Respir J. 2002;19(2):217-224.

33. Briggs DD Jr, Covelli H, Lapidus R, Bhattycharya S, Kesten S, Cassino C. Improved daytime spirometric efficacy of tiotropium compared with salmeterol in patients with COPD. Pulm Pharmacol Ther. 2005;18(6):397-404.

34. van Noord JA, Aumann JL, Janssens E, et al. Comparison of tiotropium once daily, formoterol twice daily and both combined once daily in patients with COPD. Eur Respir J. 2005;26(2):214-222.

35. Hanania NA, Boota A, Kerwin E, Tomlinson L, Denis-Mize K. Efficacy and safety of nebulized formoterol as add-on therapy in COPD patients receiving maintenance tiotropium bromide: Results from a 6-week, randomized, placebo-controlled, clinical trial. Drugs. 2009;18:69(9):1205-1216.

36. Donohue JF, Fogarty C, Lötvall J, et al; for INHANCE Study Investigators. Once-daily bronchodilators for chronic obstructive pulmonary disease: indaceterol versus tiotropium. Am J Respir Crit Care Med. 2010;182(2):155-162.
37. Buhl R, Dunn LJ, Disdier C, et al; for INTENSITY study investigators. Blinded 12-week comparison of once-daily indacaterol and tiotropium in COPD. Eur Respir J. 2011;38(4):797-803.

38. Kerwin E, Hébert J, Gallagher N, et al. Efficacy and safety of NVA237 versus placebo and tiotropium in patients with COPD: the GLOW2 study. Eur Respir J. 2012;40(5):1106-1114.

39. Jara M, Wentworth C 3rd, Lanes S. A new user cohort study comparing the safety of long-acting inhaled bronchodilators in COPD. BMJ Open. 2012;2(3):e000841.

40. Medicines and Healthcare Products Regulatory Agency. Tiotropium. Safety studies of Spiriva Respimat. 2010. Available from http://www. mhra.gov.uk/Safetyinformation/DrugSafetyUpdate/CON099869. Accessed February 12, 2013.

41. Wilt TJ, Niewoehner D, MacDonald R, Kane RL. Management of stable chronic obstructive pulmonary disease: a systematic review for a clinical practice guideline. Ann Intern Med. 2007;147(9):639-653.

42. Oba Y, Zaza T, Thameem DM. Safety, tolerability and risk benefit analysis of tiotropium in COPD. Int J Chron Obstruct Pulmon Dis. 2008;3(4):575-584.

43. Decramer M, Molenberghs G, Liu D; for UPLIFT investigators. Respir Med. 2011;105(10):1523-1530.

44. Breekveldt-Postma NS, Koerselman J, Erkens JA, Lammers JW, Herings RM. Enhanced persistence with tiotropium compared with other respiratory drugs in COPD. Respir Med. 2007;101(7):1398-1405.

45. Cramer JA, Bradley-Kennedy C, Scalera A. Treatment persistence and compliance with medications for chronic obstructive pulmonary disease. Can Respir J. 2007;14(1):25-29.

46. Short PM, Williamson PA, Elder DH, Lipworth SI, Schembri S, Lipworth BJ. The impact of tiotropium on mortality and exacerbations when added to inhaled corticosteroids and long-acting $\beta$-agonist therapy in COPD. Chest. 2012;141(1):81-86.
International Journal of COPD

\section{Publish your work in this journal}

The International Journal of COPD is an international, peer-reviewed journal of therapeutics and pharmacology focusing on concise rapid reporting of clinical studies and reviews in COPD. Special focus is given to the pathophysiological processes underlying the disease, intervention programs, patient focused education, and self management protocols.

\section{Dovepress}

This journal is indexed on PubMed Central, MedLine and CAS. The manuscript management system is completely online and includes a very quick and fair peer-review system, which is all easy to use. Visit http://www.dovepress.com/testimonials.php to read real quotes from published authors. 